\title{
CHOCOLATE DAS BAGAS E CLOROSE FOLIAR: ANOMALIA DA VIDEIRA CAUSADA POR DEFICIENCIA DE BORO ( $\left.{ }^{(}\right)$
}

\author{
HUGO KUNIYUKI $\left({ }^{2,5}\right)$, MAURILO MONTEIRO TERRA $\left({ }^{3,5}\right)$, RÛTER HIROCE $\left({ }^{4}\right)$ \\ e ÁLVARO SANTOS COSTA ( ${ }^{2}$ )
}

\begin{abstract}
RESUMO
A anomalia do cultivar de videira Niagara Rosada, caracterizada por sintomas de clorose nas folhas, chocolate das bagas e cachos malformados, nao é de natureza virótica, de acordo com resultados de testes de transmissáo e de perpetuação. Essa anomalia, presente em áreas definidas de alguns vinhedos de Indaiatuba e Jundiaí (SP), está associada à defíciência nutricional de boro. $\mathrm{O}$ teor médio de boro $\mathrm{em}$ amostras de plantas afetadas de 'Niagara Rosada' (18 ppm no limbo e $7 \mathrm{ppm}$ nos frutos) foi menor do que nas de plantas normais (24 ppm no limbo e $10 \mathrm{ppm}$ nos frutos) das mesmas plantaçoes; um material coletado de um vinhedo bastante afetado mostrou 13 e $1 \mathrm{ppm}$ respectivamente no limbo e nos frutos de plantas deficientes contra 20 e 6 ppm nos de plantas sem sintomas. Amostras de três vinhedos vizinhos sem essa anomalia apresentaram um teor médio de $35 \mathrm{ppm}$ no limbo. As do portaenxerto 'Traviú' com clorose e sem clorose mostraram $16 \mathrm{ppm}$ e $43 \mathrm{ppm}$ de boro respectivamente. A aplicaçđo de bórax, nas doses de 5,10 e $20 \mathrm{~g}$ por planta, logo após a poda de inverno, ou pulverizaçao de ácido bórico nas concentraçoes de $0,3 \%$ e $0,6 \%$ sobre a folhagem, durante $o$ infício do florescimento e durante a fase de uva chumbinho, permitiram controlar a anomalia nas condiçбes de campo. Foi notada resposta favorável por um ciclo vegetativo, pelo menos, indicando controle por efeito residual de uma aplicação.
\end{abstract}

Termos de indexação: Vitis spp., anomalia fisiológica, micronutriente, controle.

( ${ }^{1}$ ) Trabalho apresentado, em parte, no V Congresso Paulista de Fitopatologia, 18-20 de janeiro de 1982, Piracicaba (SP). Recebido para publicação em 27 de jeneiro de 1984.

( ${ }^{2}$ ) Seção de Virologia Fitotécnica, Instituto Agronomico (IAC), Caixa Postal 28, 13100 - Campinas (SP).

$\left({ }_{4}^{3}\right)$ Seção de Viticultura, IAC.

$\left({ }_{5}^{4}\right)$ Seção de Química Analítica, IAC.

( ${ }^{5}$ ) Com bolsa de suplementação do CNPq. 


\section{INTRODUCAOO}

Uma anomalia do cultivar de videira Niagara Rosada (Vitis labrusca L. $\mathrm{x} V$. vinifera $\mathrm{L}$.), caracterizada por sintomas de clorose das folhas, necrose da polpa dos frutos e cachos malformados, vem sendo observada desde 1974 em plantações nas regióes de Indaiatuba e Jundiaf (SP). Essa anomalia, chamada de "chocolate" pelos viticultores, devido aos sintomas internos das bagas, apresenta importância econômica, pois causa consideráveis perdas na produção de uva das plantas afetadas.

Nos estudos para determinação do agente causal, ela foi inicialmente julgada como associada à infecção por vírus, micoplasma ou riquétzia, pelo fato de alguns dos seus sintomas serem semelhantes aos induzidos por esses patógenos em videiras cultivadas em outros países (CAUDWELL, 1964; GOODING \& TELIZ, 1970; HEWITT, 1970). Além disso, não foi encontrada evidência de que ela estivesse relacionada com organismos do solo ou da parte aérea ou, ainda, com toxicidade decorrente da aplicação inadequada de defensivos as videiras.

Concomitantemente aos estudos visando verificar a natureza infecciosa da anomalia, foi também formulada a hipotese de que o "chocolate" poderia estar relacionado com deficiência nutricional, pois alguns dos sintomas são semelhantes aos descritos para carência de certos elementos em videira em outros países (BRANAS \& BERNON, 1954; CHRISTENSEN et alii, 1978; COOK et alii, 1960; WINKLER et alii, 1974).

$O$ presente trabalho relata os estudos conduzidos com base nessas duas hipóteses e que resultaram na determinação de que a anomalia da videira constatada em Indaiatuba e Jundiaf estava associada à deficiência de boro.

\section{MATERIAL E MÉTODOS}

As observaçסes dos sintomas em plantas afetadas do cultivar Niagara Rosada foram feitas a partir de 1974, quando a anomalia foi assinalada pela primeira vez. Efetuaram-se três a quatro observaçóes dentro do período que vai desde a brotação de primavera até a colheita. Os experimentos de transmissão visando determinar a natureza da anomalia foram feitos sob condiçбes de casa de vegetação na Seção de Virologia do Instituto Agronômico, Campinas.

Os materiais sadios utilizados nos testes de transmissão foram constituídos de plantas de 'Niagara Rosada' e de algumas videiras indicadoras de vírus, que vinham sendo multiplicadas e mantidas na Seção de Virologia. Os 
materiais afetados foram coletados na região de Jundiaí, de plantas que exibiam fortes sintomas da anomalia. As plantas-teste destinadas à inoculação mecânica consistiram em espécies mais comuns empregadas em estudos com vírus de plantas.

As plantas utilizadas nos estudos foram conduzidas em vasos de alumínio de $15 \mathrm{~cm}$ de diâmetro e $16 \mathrm{~cm}$ de altura, e, o solo, uma mistura de Latossolo Roxo com composto em partes iguais.

Os testes de transmissão por união de tecidos foram feitos mediante enxertia de pequenos garfos herbáceos, com uma a duas gemas, de plantas com anomalia em ramos herbáceos de videira sem sintomas, para que em suas brotaçōes fosse efetuada a observaçao de sintomas. As videiras enxertadas, em sua maioria, foram mantidas sob observação durante 18 a 24 meses. Os testes de inoculação mecânica por friç̧ão de suco foram executados com inóculo obtido pela maceraçáo dos tecidos de videira afetada em presença de uma solução de nicotina a $2,5 \%$ em água (DIAS, 1965) e de tampão fosfato, usualmente empregado na Seçao de Virologia. As plantas-teste submetidas à inoculação mecânica foram mantidas durante 20 a 40 dias sob observação ao lado de plantas não inoculadas.

A análise química dos tecidos de videira foi feita na Seção de Química Analítica do Instituto Agronômico. As amostras, comparáveis, consistiram em folhas do terço superior dos ramos e frutos verdes de plantas aparentemente normais e afetadas de 'Niagara Rosada', que cresciam dentro de áreas proximas de mesma plantação. Também foi feita análise para folhas com e sem sintomas do porta-enxerto 'Traviú' ( $V$. riparia Michaux. $\mathrm{x} V$. rupestris Scheele x $V$. cordifolia Michaux., '106-8').

Os testes de aplicação de boro foram executados por um dos autores em uma plantação de 'Niagara Rosada', com oito anos de idade, localizada em Indaiatuba, durante os anos de 1981 e 1982. Esse micronutriente foi fornecido de duas maneiras: (a) aplicação de bórax no solo a 5,10 e $20 \mathrm{~g}$ por planta logo após a poda de inverno e (b) pulverização de ácido bórico a $0,3 \%$ e $0,6 \%$ sobre a folhagem, uma vez durante o início do florescimento e, outra, durante a fase de uva chumbinho, para cada dose. As testemunhas eram plantas nao submetidas a tratamento, localizadas nas proximidades de plantas tratadas, que haviam apresentado sintomas típicos da anomalia na vegetação anterior.

Os materiais e métodos mais especifficos serão relatados junto à descrição de cada teste. 


\section{RESULTADOS}

\subsection{Sintomatologia}

A anomalia foi observada no cultivar Niagara Rosada, afetando um número bastante variável de plantas. Em um vinhedo de Jundiaí (SP), já se observaram cerca de 200 a 250 plantas anômalas, cujos sintomas característicos são vistos principalmente em outubro-novembro, quando os frutos ainda estão verdes. Nessa ocasião, tais plantas apresentam amarelecimento das áreas internervais das folhas terminais e cachos malformados, com bagas normais entremeadas com bagas pequenas, algumas das quais levemente alongadas e com áreas deprimidas e escuras na casca, apresentando, muitas delas, necrose da polpa, bastante visível, quando verdes (Figura 1). De modo geral, há uma associação constante entre clorose nas folhas e sintomas nos frutos. Em plantas bastante afetadas, podem ser notados paralisação de crescimento, ligeiro espessamento de alguns entrenós superiores, áreas necróticas nas margens foliares, secamento da parte apical e emissão de brotos laterais.

Clorose nas folhas foi também observada em duas plantas não enxertadas do porta-enxerto 'Traviu' que cresciam dentro de área afetada de um vinhedo.

A anomalia geralmente ocorre em áreas definidas do vinhedo, afetando plantas de diferentes idades, inclusive aquelas com um a dois anos após a enxertia.

\subsection{Tentativas de transmissão do agente causal da anomalia}

Como alguns dos sintomas da anomalia eram semelhantes aos provocados por vírus, micoplasma ou riquétzias em videiras cultivadas em outros países, foram feitos testes com o objetivo de verificar a possibilidade de a mesma ser induzida por um desses patógenos.

Plantas de estaca sadias dos cultivares de copa Carignane, Mission e Niagara Rosada e dos porta-enxertos Kober 5BB, LN-33 e Rupestris du Lot foram então enxertadas com materiais de plantas afetadas de "Niagara Rosada'. Essas videiras foram observadas durante um ano e meio a dois, mas não houve evidência de transmissão da anomalia nas brotaçðes surgidas após a enxertia nem naquelas mantidas sob observação durante cinco anos.

As tentativas de transmissão por inoculação mecânica em plantas-teste herbáceas também deram resultados negativos.

\subsection{Recuperação}

Durante as observaçбes iniciais para estudo da sintomatologia, fo- 


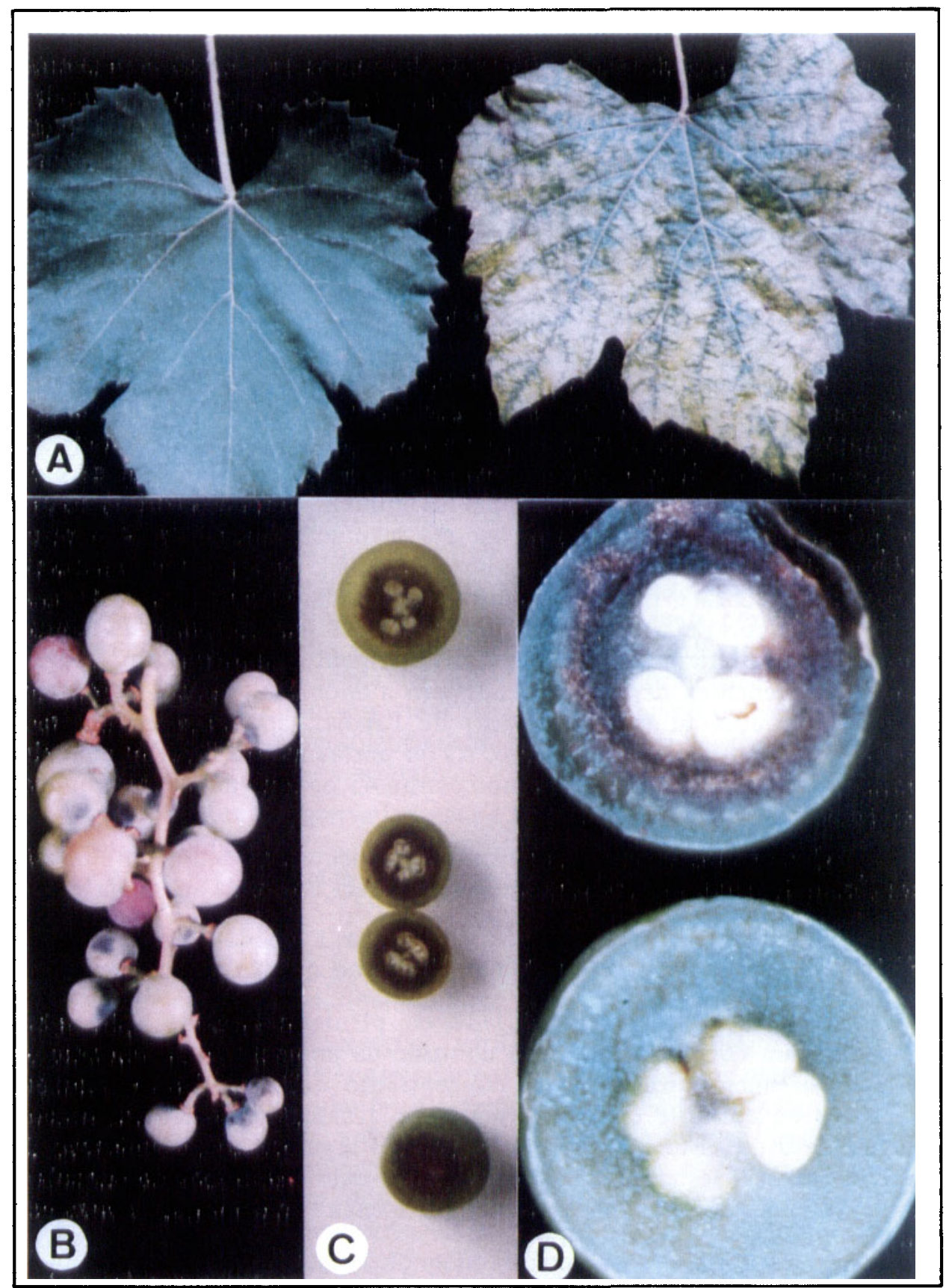

FIGURA 1 - Sintomas de deficiência de boro na videira 'Niagara Rosada'. A: Folha com clorose ao lado de uma normal; B: Cachos malformados; C e D: Chocolate das bagas. 
ram coletadas estacas das partes lenhosas dos ramos das plantas com anomalia e estabelecidas em vasos sob condiçoes de casa de vegetação para enraizamento e brotação. Em todas as plantas resultantes, não houve manifestação (recuperação) dos sin tomas na brotação surgida ainda no mesmo ciclo vegetativo da videira em que foi feita a coleta de estacas. Também não foi verifícada presença de sintomas que sugerissem perpetuação da anomalia, na vegetação seguinte ao inverno.

\subsection{Análise química dos tecidos de videira}

Paralelamente aos testes de transmissão, amostras de 'Niagara Rosada' com e sem sintomas foram coletadas para análise química no sentido de comprovar a hipótese de que a anomalia estaria associada à deficiência nutricional. Os resultados obtidos revelaram que havia menor teor de boro nas plantas afetadas (média de $18 \mathrm{ppm}$ no limbo e $7 \mathrm{ppm}$ nos frutos) do que nas normais de áreas próximas da mesma plantação (média de $24 \mathrm{ppm}$ no limbo e $10 \mathrm{ppm}$ nos frutos); uma amostra coletada de um vinhedo bastante afetado mostrou 13 e 1 ppm respectivamente no limbo e nos frutos de plantas anômalas contra 20 e $6 \mathrm{ppm}$ nos de plantas sem sintomas. Por outro lado, segundo determinaçð̃es feitas anteriormente, amostras de 'Niagara Rosada' procedentes de três vinhedos sem a anomalia, bastante próximos de uma plantação afetada da região de Jundiaí, apresentaram um teor médio de $35 \mathrm{ppm}$ de boro no limbo. As do porta-enxerto 'Traviú' com sintomas apresentaram $16 \mathrm{ppm}$ no limbo contra $43 \mathrm{ppm}$ no de plantas sem clorose da mesma plantação.

Quan to aos macro e outros micronutrientes, os dados obtidos não permitiram detectar diferenças que sugerissem relação com a anomalia.

\subsection{Resposta à aplicação de boro em campo}

Observaçðes feitas em 1981/82, em plantas nas quais se aplicou boro, permitiram concluir que houve controle da anomalia, independente da fonte desse micronutriente e da concentração utilizada. Houve também indicaçoes de controle com base no efeito residual, pois não foi notado aparecimento de sintomas no ciclo vegetativo seguinte ao da aplicação de boro. As plantas testemunhas continuaram a exibir sintomas de chocolate das bagas e clorose das folhas, da mesma maneira que muitas plantas não tratadas do vinhedo considerado.

Em 1983, a anomalia foi controlada nas partes afetadas dessa plantação, mediante aplicação de boro pelo próprio viticultor na base de $10 \mathrm{~g}$ de bórax no solo por planta ou $3 \mathrm{~g} /$ litro de ácido borico no início do florescimento e $3 \mathrm{~g} /$ litro na fase de uva chumbinho. 


\section{DISCUSSAO}

Os resultados negativos obtidos nas tentativas de transmissão e de perpetuação indicaram experimentalmente que o chocolate das bagas e clorose das folhas de 'Niagara Rosada' nao constituem problema de natureza infecciosa, como se supôs inicialmente. Observaçðes nos locais afetados indicaram também que a anomalia não estava relacionada com doenças de fungos, infestaçoes de ácaros ou insetos ou com toxicidade por defensivos, corretivos ou outros produtos químicos. Assim sendo, a única evidência encontrada foi que a anomalia poderia estar relacionada com condiçðes do solo, devido a sua ocorrência em áreas definidas da plantação.

Os resultados da análise química de amostras comparáveis de folhas e frutos de plantas de 'Niagara Rosada' e de folhas do porta-enxerto 'Traviu' revelaram que havia sempre menor teor de boro nas afetadas do que nas normais. Além disso, os teores médios de boro obtidos para as folhas de plantas anômalas mostraram-se bastante inferiores aos das amostras de plantas de mesmo cultivar provenientes de vinhedos normais, porém de localidades próximas de uma das plantaçóes com anomalia da região de Jundiaí. Isso parece indicar que as plantas aparentemente normais de vinhedos com anomalia já se encontram com teor relativamente baixo do micronutriente, sendo de supor que poderão apresentar chocolate das bagas e clorose foliar dentro dos próximos ciclos vegetativos.

Os sintomas observados para a anomalia presente em 'Niagara Rosada' são, em linhas gerais, semelhantes aos descritos para a deficiência de boro em algumas viníferas cultivadas em outros países; o chocolate foi notado na França (BRANAS \& BERNON, 1954), mas não na Califórnia (COOK et alii, 1960). Como as variedades estudadas nesses dois países não são comuns, não há possibilidade de decidir se a presença ou ausência de chocolate é diferença varietal ou local.

Ainda nessas observaçðes, verificou-se que, de modo geral, existe uma associação constante entre clorose nas folhas e chocolate das bagas. Além disso, em algumas plantas, foi notada uma manifestação tardia de clorose foliar, sem afetar a aparência dos frutos. Entretanto, essas mesmas plantas, que haviam sido marcadas, voltaram a exibir os sintomas de clorose, acompanhados, porém, de escurecimento interno das bagas, na vegetação seguinte. Isso indica que os sintomas nas folhas e nos frutos são decorrentes de uma mesma causa e que, pelo menos no cultivar Niagara Rosada, a necrose da polpa somente ocorre quando o teor de boro na planta se situa abaixo de um nível crítico, não determinado. Diante da verificação de que o surgimento da clorose foliar parece ser anterior ao do chocolate das bagas, é bem provável que a manifestação daquela possa constituir uma indicação da 
necessidade de adotar medidas de controle, a fim de evitar frutos anômalos nos ciclos seguintes.

A aplicação de boro em plantas com sintomas nas condiçбes de campo promoveu o controle da anomalia, independente de a fonte desse micronutriente ser borax ou ácido bórico e das concentraçðes empregadas. Não foram feitos testes específicos no sentido de determinar a concentração mínima de boro que pudesse solucionar o problema, pois o objetivo deste trabalho foi apenas verificar a associaça existente entre esse micronutriente e a anomalia. Contudo, as concentraçóes mais baixas usadas nos testes poderiam ser recomendadas, pois, além de dar resposta favorável por um ciclo vegetativo, evitariam, pelo menos, gasto desnecessário. Pulverizações repetidas de adubo foliar completo também podem produzir efeito positivo, pois isso foi notado em Jundiaí, há vários anos, quando um viticultor procedeu à adubação foliar por mais de uma vez em toda a plantação, inclusive nas videiras anômalas.

Todos esses fatos constituem evidência de que a anomalia presente em algumas plantaçôes de Jundiaí e de Indaiatuba estava associada à deficiência nutricional de boro.

Até o presente, ela foi observada apenas na 'Niagara Rosada'. Isso decorre, possivelmente, do fato de as plantas desse cultivar serem mais exigentes em boro do que as de outros cultivares plantados nas regiões afetadas, sendo as primeiras a manifestar sintomas de deficiência, quando ocorre redução do teor desse micronutriente no solo. Contudo, plantas dos outros cultivares também já devem apresentar baixa concentração de boro nesses locais, embora não reconhecível visualmente; nesse caso, seria de esperar melhoria na produção e qualidade dos frutos, com o simples suprimento de boro como nutriente. De qualquer forma, o aparecimento da anomalia mostra que o solo de certas áreas vitícolas do Estado já se está tornando deficiente nesse micronutriente e que o cultivar Niagara Rosada pode constituir indicador do estado nutricional de um vinhedo com relação ao boro.

$O$ aparecimento da sua deficiência em videira provavelmente resulte do seu baixo teor no solo devido à falta de adubação adequada. As secas prolongadas, tão comuns durante o inf́cio da vegetação das videiras em São Paulo, podem ter contribuído para agravar o fenômeno, pois tais condiçðes ambientes dificultam a mineralização da matéria orgânica e, conseqüentemente, reduzem o teor de boro assimilável do terreno (MALAVOLTA, 1967). A existência dessa relação já é conhecida para algumas culturas, inclusive videira, em outros países (COOK et alii, 1960).

Tratando-se de problema nutricional, considera-se que a anomalia pode ser efetivamente controlada mediante a aplicação de produto que contém boro, seja no solo, seja por meio de pulverização foliar. 


\section{SUMMARY}

\section{INTERNAL BROWNING ("CHOCOLATE") AND LEAF CHLOROSIS OF THE 'PINK NIAGARA' GRAPE, A BORON DEFICIENCY ANOMALY}

The 'pink Niagara' grape ( $V$. labrusca $L . \times V$. vinifera L.) anomaly characterized by leaf chlorosis and "chocolate' (internal browning) of the young fruit, at first thought to be a virus disease, has been found to be a result of boron deficiency. The anomaly was first recorded in 1974. It occurs in patches in vineyards of Indaiatuba and Jundiaí, two grape-growing counties of the State of São Paulo, Brazil. Affected plants show yellowing between the primary and secondary veins of the upper leaves and mal formed clusters, with normal-sized berries and small ones. Some small fruits are slightly elongated and show dark areas on the skin; many have dark brown pulp, easily visible when they are still green. Severely affected plants become stunted. Chemical analysis showed a lower boron content in the affected plants (18 ppm in the leaf blades and $7 \mathrm{ppm}$ in the fruit) than in normal ones (24 ppm in the leaf blades and $10 \mathrm{ppm}$ in the fruit). Leaf samples from three nearby vineyards without the anomaly presented a boron content of $35 \mathrm{ppm}$. Leaf blades from abnor$\mathrm{mal}$ and normal 'Traviú' rootstocks ( $V$. riparia Michaux. $\mathrm{x} V$. rupestris Scheele $\mathrm{x}$ $V$. cordifolia Michaux., '106-8') had $16 \mathrm{ppm}$ and $43 \mathrm{ppm} \mathrm{B}$, respectively. An efficient control of the anomaly was got with borax, applied after prunning to affected plants at the rates of 5,10 and $20 \mathrm{~g}$ per plant, or with boric acid at the concentrations of 0.3 and $0.6 \%$ sprayed at flowering and when the fruits were small. There was a residual effect of the treatment on the anomaly for at least one more season.

Index terms: Vitis spp., phy siologic anomaly, micronutrient, control.

\section{REFEREANCIAS BIBLIOGRÁFICAS}

BRANAS, J. \& BERNON, G. Le plomb de la vigne, manifestation de la carence de bore. Comptes Rendus d'Academie d'Agriculture de France, Paris, 40:593-596, 1954.

CAUDWELL, A. Identification d'une nouvelle maladie a virus de la vigne, la "Flavescence dorée". Étude des phénoménes de localisation des symptômes et de rétablissement. Paris, I.N.R.A., 1964. 193p. (Annales des Épiphyties, v. 15, no. hors série I)

CHRISTENSEN, L.P., KASIMATIS, A.N. \& JENSEN, F.L. Grapevine nutrition and fertilization in the San Joaquim Valley. Berkeley. University of California, Division of Agricultural Sciences, 1978. 40 p.

COOK, J.A., LYNN, C.D. \& SISSLER, J.J. Boron deficiency in California vineyards. American Journal of Enology and Viticulture, Davis, 11:185194, 1960.

DIAS, H.F. Mechanical transmission of viruses to herbaceous hosts, In: INTERNATIONAL CONFERENCE ON VIRUS AND VECTOR ON PERENNIAL HOSTS, WITH SPECIAL REFERENCE TO VITIS, Davis, 1965. Proceedings. Davis, University of California, Division of Agricultural Sciences, p. 235-247. 
GOODING, G.V. \& TELIZ, D. Grapevine yellow vein. In: FRAZIER, N.W. ed. Virus diseases of small fruits and grapevines. Berkeley, University of California, Division of Agricultural Sciences, 1970. p.238-241.

HEWITT, W.B. Pierce's disease of Vitis species. In:FRAZIER, N.W. ed. Virus diseases of small fruits and grapevines. Berkeley, University of California, Division of Agricultural Sciences, 1970. p.196-200.

MAlaVolta, E. Manual de adubação química. 2.ed. São Paulo, Ceres, 1967. 606p.

WINKLER, A.J., COOK, J.A., KLIEWER, W.M. \& LIDER, L.A. General viticulture. 2. ed. Berkeley, University of California Press, 1974. 710p. 